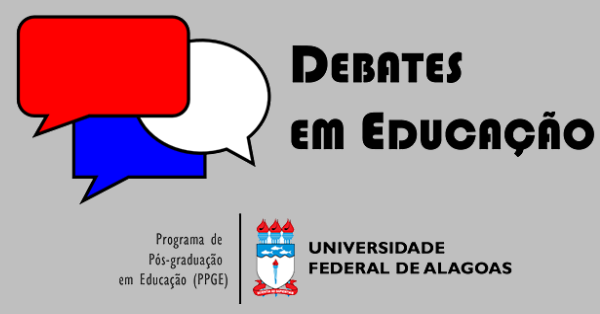

ISSN Eletrônico 2175-6600

Vol. 13 I Número Especial 2 I 2021

Gabriela Paim Rosso
Universidade Federal de Santa Maria (UFSM)
gabip.rosso@gmail.com

Marilene Gabriel Dalla Corte

$\theta$ iD

Universidade Federal de Santa Maria (UFSM) marilenedallacorte@gmail.com

\section{A EXTENSÃO UNIVERSITÁRIA NO CURRÍCULO DE CURSOS DE GRADUAÇÃO E CONTEXTOS EMERGENTES}

\section{RESUMO}

Discute-se nesta produção a inserção da extensão universitária no currículo de cursos de graduação e sua inter-relação com contextos emergentes na Educação Superior. É decorrente de pesquisa qualitativa, estudo de caso, balizada na análise dos documentos institucionais e nas respostas de questionário misto com doze coordenadores de cursos de graduação da Universidade Federal de Santa Maria. Conclui-se que a inserção da extensão na matriz curricular de cursos de graduação constitui-se emergente por que: potencializa a perspectiva da qualidade na formação profissional; assume o estudante como protagonista e sistematizador do seu aprendizado em campo de atuação profissional; articula o currículo às ações político-pedagógica dos cursos; promove a interdependência e interlocução universidade e sociedade.

Palavras-chave: Educação Superior. Extensão Universitária. Cursos de Graduação. Contextos Emergentes. Currículo.

\section{UNIVERSITY EXTENSION IN THE CURRICULUM OF UNDERGRADUATE COURSES AND EMERGING CONTEXTS}

\begin{abstract}
This production discusses the insertion of university extension in the curriculum of undergraduate courses and its interrelation with emerging contexts in Higher Education. It is the result of qualitative research, a case study, based on the analysis of institutional documents and the answers to a mixed questionnaire with thirteen coordinators of undergraduate courses at the Federal University of Santa Maria. It is concluded that the insertion of the extension in the curriculum of undergraduate courses is emerging because: it enhances the perspective of quality in professional training; assumes the student as the protagonist and systematizer of their learning in the field of professional performance; articulates the curriculum to the politicalpedagogical actions of the courses; promotes interdependence and dialogue between university and society.
\end{abstract}

Keywords: Higher Education. University Extension. Undergraduate Courses. Emerging Contexts. Curriculum.

Submetido em: 29/10/2020

Aceito em: 15/04/2021

Publicado em: 30/11/2021

do https://doi.org/10.28998/2175-6600.2021v13nEsp2p365-388 


\section{INTRODUÇÃO}

A inserção da extensão universitária na dinâmica curricular dos cursos de graduação constitui-se emergente nas constantes mudanças e transformações que abrangem as Instituições de Ensino Superior (IES), justamente porque delineia (re)articulações na maneira de pensar e agir na e da universidade em interlocução com a sociedade. Nesta perspectiva, refletir e debater a extensão em contexto emergente nos cursos de graduação contribui para reconhecer a necessidade de reorganização do modelo curricular de ensino na Educação Superior, considerando as diferentes realidades apresentadas pelas IES brasileiras e o efetivo diálogo entre ensino, pesquisa e extensão.

A extensão universitária constitui-se emergente no currículo dos cursos superiores, uma vez que o Plano Nacional de Educação (PNE 2014/2024), Lei n. 13.005/2014, prevê na meta 12.7 , no mínimo, $10 \%$ do total de créditos curriculares exigidos para graduação em ações de extensão, tornando-se desafiadora a sua implementação curricular de maneira articulada ao projeto político-pedagógico dos cursos de graduação (BRASIL, 2014).

Ocorre que, por muito tempo, a extensão esteve à margem na relação com o ensino e a pesquisa, obtendo caráter assistencialista e de pouca valoração no meio acadêmico, legitimando o enaltecimento da relação vertical da universidade com o meio social apenas como prestadora de serviços. A inserção da extensão como créditos curriculares para os cursos de graduação transcende a concepção hegemônica, assistencialista, elitista e isolada das ações universitárias, o que direciona para uma concepção emancipatória, crítica e reflexiva dos processos formativos em suas demandas sociais e profissionais, repercutindo em novos movimentos de reorganização do modelo curricular vigente.

Assim, parte-se do pressuposto de que a extensão universitária caracterizada por programas, projetos, cursos e oficinas, eventos e prestação de serviços, entre outras práticas e processos formativos inter-relacionados a ações de inserção e interlocução socioeducativa, constitui-se num dos pilares do tripé universitário e, portanto, precisa ser pensada, priorizada e articulada como ação político-formativa indispensável ao currículo de cursos de graduação, entre outros cursos.

Considerando as premissas iniciais, este texto foi produzido a partir dos estudos, discussões e constatações de uma pesquisa junto ao Programa de Pós-graduação em Educação da Universidade Federal de Santa Maria (UFSM) no bojo dos estudos do Grupo de Pesquisa Gestar/CNPq, problematizando as políticas públicas de extensão 
universitária e sua dinamização curricular em cursos de graduação, em contextos emergentes na Educação Superior. Problematizou-se, portanto, na perspectiva dos contextos emergentes na educação superior e atuais políticas públicas, quais aspectos estão relacionados à inserção das ações de extensão nos currículos de cursos de graduação da Universidade Federal de Santa Maria (UFSM)? E, com base na problemática, por objetivo geral focou-se em analisar a perspectiva dos contextos emergentes na Educação Superior e as atuais políticas públicas, considerando aspectos relacionados à inserção da extensão nos currículos de cursos de graduação, da Universidade Federal de Santa Maria (UFSM).

O texto está dividido em seções sendo elas: "a extensão universitária no currículo de cursos de graduação", em que se prioriza discutir a concepção histórica e política da extensão nas normativas educacionais brasileiras e na América Latina, a função social da universidade em contexto local e global e refletir a política de inserção da extensão no currículo como contexto emergente; em "caminhos metodológicos" apresenta-se o delineamento da pesquisa; em "inserção e articulação da extensão em cursos de graduação da UFSM" apresenta-se os cursos de graduação envolvidos na pesquisa e as perspectivas de inserção da extensão universitária na/da UFSM em contextos emergentes; e, por fim, nas considerações finais, abordam-se as conclusões acerca da problemática que atravessa o campo dos contextos emergentes na perspectiva da extensão universitária no currículo da graduação.

\section{A EXTENSÃO UNIVERSITÁRIA NO CURRÍCULO DE CURSOS DE GRADUAÇÃO}

Na história da educação brasileira a extensão universitária constitui um marco nas relações estudantis e um elo entre universidade e sociedade. Historicamente, as vertentes extensionistas tencionaram uma relação de poder e postura hierárquica de conhecimento entre universidade e sociedade, em que a primeira era concebida como fonte exclusiva de saber, e a segunda como receptora desse conhecimento.

É possível compreender por meio do percurso histórico e político da Educação Superior, em âmbito global e local, em inter-relação com os contextos emergentes, que a extensão universitária conquistou diversas frentes, perspectivas e atribuições de acordo com as demandas sociais, políticas e econômicas de cada época, as quais influíram e ainda influem na concepção de sua ação no contexto das IES. 
Por muito tempo, a extensão esteve à margem das normativas educacionais, sendo que sua legitimidade foi firmada somente a partir dos marcos de democratização da educação pelas políticas nacionais brasileiras, em que passou a ser referenciada como uma função de destaque das IES na articulação do tripé universitário. A representatividade estudantil e de órgãos como o Fórum de Pró-Reitores de Extensão (FORPROEX11) marcaram essa conquista e a reformulação do pensar e agir das universidades brasileiras. Cabe destacar que, o que hoje compreendemos como extensão advém das influências do contexto histórico e político vivido no âmbito da educação brasileira e da América Latina em seus diversos períodos.

As influências do período ditatorial ainda são recentes e marcantes na concepção de formação e atuação das IES. O regime militar possibilitou a institucionalização das ações de extensão no contexto das universidades e muitas ações extensionistas se legitimaram neste período. No entanto, seu legado compõe e reforça o paradigma de uma universidade elitista e hegemônica aos preceitos formativos, que influiu na organização dos cursos de graduação e de seus currículos de maneira segregada e, consequentemente, na formação social.

A política de extensão da UFSM (2008, p. 15), em sua concepção geral, apresenta ações extensionistas na perspectiva de "[...] convivência extramuros, tanto no sentido de integração das atividades acadêmicas de ensino e pesquisa com outras comunidades universitárias do país e do mundo", como também no "[...] relacionamento efetivo com as comunidades leigas da sua região". Nessa mesma lógica, a política institucional da UFSM delineia como ações extensionistas programas, projetos, cursos, eventos, prestação de serviços, publicações e outros produtos acadêmicos, sendo que é livre a organização por áreas temáticas e linhas de curso. Considerando os preceitos das políticas públicas globais, nacionais e locais, a UFSM passa por um processo de reestruturação curricular para atender as demandas de inserção da extensão no currículo dos cursos de graduação, via políticas educacionais vigentes.

Com a inserção curricular, proposta pelo PNE (2014-2024), as IES brasileiras passaram a repensar suas concepções e práticas extensionistas, tanto no que se referem à infraestrutura, formas de operacionalização, atribuição de responsabilidades

\footnotetext{
1 O Fórum de Pró-Reitores de Extensão das Instituições Públicas de Educação Superior Brasileiras é uma entidade voltada para a articulação e definição de políticas acadêmicas de extensão, comprometida com a transformação social para o pleno exercício da cidadania e o fortalecimento da democracia. São membros natos do Fórum de Pró-Reitores de Extensão das Instituições Públicas de Educação Superior Brasileiras, com direito a voz e voto, os Pró-Reitores de Extensão e titulares de órgãos congêneres das Instituições de Ensino Superior Públicas Brasileiras. (RENEX, 2016).
} 
administrativas e pedagógicas, como na definição e execução de suas políticas e atribuições de fomento, a fim de priorizar a formação dos estudantes na perspectiva de propostas interdisciplinares voltadas às demandas da sociedade, aos contextos de atuação profissional e à dinâmica curricular dos cursos de graduação.

A extensão pensada e articulada sob a ótica do PNE (2014-2024) transcende a novos arranjos didático-metodológicos e na própria reformulação do ensino. Segundo Imperatore e Pedde (2015), a discussão para sua implementação é epistemológica², com foco na construção de pensamentos coerentes às novas linguagens e experiências no contexto formativo acadêmico. Assim, sua implementação no currículo dos cursos de graduação requer a convergência de saberes e fazeres necessários à institucionalização de novos modos de pensar e articular o pedagógico à reformulação das Propostas Pedagógicas da Universidade, indispensável ao atendimento das necessidades e exigências da sociedade e para repensar a prática como submissão à lógica do mercado.

Gadotti (2017, p. 04) coloca que "[...] aclarar o que entendemos por extensão, é fundamental para caminhar nesse território decisivo para a necessária reforma da universidade e para a radicalização da democracia". Ainda, a extensão universitária requer estar além das relações terminológicas e assistenciais, entrecruzada às dimensões do ensino e da pesquisa, em provimento ao caráter formativo e de elevação social e acadêmica das IES (SANTOS, 2011).

Com a finalidade de promover um diálogo e análise das propostas curriculares que preveem as ações extensionistas nos cursos de graduação, discute-se a inserção da extensão no currículo acadêmico, na lógica dos contextos emergentes, referendada por Morosini (2014). A autora aborda contextos emergentes como configurações em construção na Educação Superior, as quais são observadas em sociedades contemporâneas e que convivem em tensão com concepções pré-existentes. Tais configurações constituem refletoras de tendências históricas, a partir do espaço de transição entre um modelo ideal weberiano de educação tradicional e outro de Educação Superior sob a égide neoliberal.

Nessa direção, Dalla Corte (2017) destaca que a conjuntura dos contextos emergentes está imbricada às transformações que acontecem no contexto das IES, diante as demandas sociais, culturais, econômicas, difundidas por políticas públicas globais e locais. Essas transformações implicam uma nova cultura e reorganização da

\footnotetext{
2 A fim de conceituar a terminologia no âmbito da extensão universitária, utiliza-se a definição em um sentido amplo como "o estudo metódico e reflexivo do saber, de sua organização, de sua formação, de seu desenvolvimento, de seu funcionamento e seus produtos intelectuais" (JAPIASSU, 1991, p. 16).
} 
Educação Superior de uma realidade multifacetada, apresentada nos diferentes contextos sociais. Ainda, para a autora, os contextos emergentes abrangem a conjuntura de novas direções, desafios, exigências, formas de fazer e realidades que influem às transformações e desafios da "sociedade do conhecimento", diante a dinamicidade vivida na "era tecnológica"3.

Estamos acompanhando cotidianamente novas formas de pensar e agir em sociedade, o que requer aos sujeitos sociais, históricos e culturais a busca por [re]configurações e atualizações nas maneiras de [con]viver e produzir em sociedade. Tais buscas incidem em aprender a [con]viver como um emaranhado de informações e tecnologias que exigem uma cultura organizacional diferenciada no que diz respeito a compreensão e ao uso de ferramentas digitais e softwares avançados, os quais contém novas formas e exigências de manuseio, além de múltiplas possibilidades de interlocução e produção técnica e científica. (DALLA CORTE, 2017, p. 359)

A partir dos conceitos apresentados por Morosini (2014) e Dalla Corte (2017), percebe-se os desafios da extensão universitária em contexto emergente e, portanto, envolvida diretamente com a formação superior na e para a vida em sociedade, justamente porque os processos formativos na graduação necessitam considerar possibilidades de atuação, interlocução e qualificação profissional com base nas demandas sociais.

Gadotti (2013, p. 02), que discute a qualidade social, traz a perspectiva de melhoria da condição de vida de todas as pessoas, já que na educação, "[...] a qualidade está ligada diretamente ao bem-viver de todas as nossas comunidades, a partir da comunidade escolar", ou seja, "[...] não há qualidade na educação sem a partição da sociedade". A extensão universitária em contexto emergente tem o compromisso e potencial com a qualidade social e, portanto, como partícipe na promoção do desenvolvimento sustentável ${ }^{4}$ na perspectiva de universidade socialmente relevante.

Apesar de sua relevância acadêmica e do contexto histórico-político atual estarem apoiados na articulação das atividades extensionistas junto ao currículo dos cursos de graduação, e que isso repercute na mudança de paradigma da Educação Superior, ainda

3 Para Mota (2013), a concepção de "sociedade do conhecimento" e a "nova era tecnológica" estão imbricadas na velocidade e simultaneidade com que a informação chega e acontece na sociedade, exigindo uma postura reflexiva sobre o cenário de atuação onde métodos tradicionais de ensino são colocados a prova, assim como o saber profissional e a atuação contínua de construção e reconstrução do conhecimento.

${ }^{4}$ De acordo com a Política Nacional de Extensão do FORPROEX (2012) cabe destacar a concepção de desenvolvimento sustentável à universidade como instância produtora de conhecimento, capaz de oferecer aos governos e à sociedade as tecnologias, teorias e processos, assim como profissionais capazes de propulsionar desenvolvimento social e humano. De acordo com o documento, para que esse desenvolvimento não se restrinja à esfera econômica, seja sustentável e tenha um caráter ético, é preciso que esses 'produtos' estejam afinados com os valores e interesses sociais. 
existem questionamentos quanto a sua efetivação e concepções do tripé ensino, pesquisa e extensão que baliza as ações e as concepções das IES (RODRIGUES, 2003).

Para Mazzili (2014), essa perspectiva se constitui desafiadora, uma vez que o exercício de articulação do tripé universitário é um fator preponderante na referência de padrão de qualidade para as IES brasileiras, as quais baseiam seus princípios na minimização das desigualdades sociais, culturais e econômicas e que buscam uma formação democrática e igualitária.

De acordo com Morosini (2014), as acepções do mercado de trabalho vêm expandindo movimentos de concepções paradigmáticas de Educação Superior, voltadas ao tensionamento da eficiência, eficácia, relevância e efetividade ao padrão de excelência a este nível de ensino. No entanto, Maués (2019) discute que a lógica das IES em ter como missão o alcance de excelência de sua efetividade pode significar tanto um alcance de um padrão de qualidade por estas instituições, como sua classificação nos rankings internacionais. Por isso, a importância de se ter clareza nos critérios de autonomia universitária que incidem no planejamento, na articulação, na consecução e avaliação das práticas político-pedagógicas de gestão universitária e respectivos processos formativos.

Pensar a qualidade de ações extensionistas inseridas no currículo de cursos de graduação, faz refletir sobre uma nova concepção para Educação Superior, para além da formação técnico-científica, a fim de potencializar também formação social, humana e cultural nas IES, o que repercute em reconhecer e compreender contextos emergentes e seus impactos aos processos de gestão universitária em seus aspectos administrativo, pedagógico e financeiro. Assim, a extensão apresenta-se como uma possibilidade de estreitar as relações entre as IES e os múltiplos campos de atuação profissional e, sobremaneira, de qualificar a inserção social da universidade em suas diversas contribuições com a sociedade, para além do assistencialismo e prestação de serviços.

Além disso, a perspectiva sobre a concepção da extensão engajada ao currículo pelo viés da qualidade social, a fim de proporcionar a interação dialógica, interdisciplinar e interprofissional dos conhecimentos, poderá possibilitar impacto na formação dos estudantes e na transformação da sociedade. No entanto, cabe considerar que dependendo do campo de atuação, dos princípios, objetivos e interesses das IES, bem como a perspectiva global, nacional e local de mercado e de governo, a concepção de qualidade poderá se constituir isomórfica, da especificidade ou equitativa (MOROSINI, 2014) e estas questões estão intimamente imbricadas com os processos de ensino, pesquisa e extensão universitária. Em outras palavras, se a extensão universitária continuar sendo compreendida sob a concepção assistencialista, certamente, os 
processos formativos da e na universidade estarão comprometidos quanto a real interrelação desta dimensão do tripé universitário com as demandas sociais, a identidade e o estatuto dos cursos de graduação, bem como a inserção profissional no mercado de trabalho.

É importante compreender que o paradigma dominante e predominante na historicidade das universidades infere na compreensão das concepções de extensão. Por essa lógica, prioriza-se, além da relação assistencial e de prestação de serviços, o campo de formação que ultrapassa a hegemonia do ensino e da pesquisa e dos muros da universidade. Esse tensionamento tem proporcionado uma nova concepção sobre a qualidade das universidades para a formação discente, em suas diversas facetas de atuação, entendendo a extensão articulada ao currículo e respectivos processos formativos dos cursos de graduação como uma possibilidade frutífera de inserção social e interlocução da universidade.

A inserção das ações extensionistas no currículo de cursos de graduação desafia as IES a assumirem a responsabilidade de seu planejamento, no sentido de contemplarem na gestão político-pedagógica, processos qualitativos pertinentes à realidade vivida pela instituição. Segundo Lunardi (2012, p. 67):

A relação qualidade na educação superior está intrinsecamente agregada à cultura estabelecida pelos cursos de formação, bem como repercute nos contextos educacionais em que os professores atuam. Examinar as questões que envolvem [...], em especial na cultura da Instituição de Ensino Superior (IES) e nas práticas que qualificam a formação pretendida com o enfoque no eixo da gestão pedagógica universitária, exige que se olhe sobre o viés de um ensino eficaz.

A autora aborda que a Instituição de Ensino Superior precisa estar articulada à organização e condução de todo processo educativo, com critérios bem definidos; isso determina para onde a instituição quer ir, porque, com quem e como alcançará seus propósitos. Também, defende que possam ser legitimados pela gestão pedagógica padrões mínimos que garantam que as necessidades da instituição sejam bem atendidas, alcançando o aprimoramento dos ambientes, gestão e organização da instituição, de ensino-aprendizagem e das relações no contexto educacional.

Portanto, conceber a extensão vinculada ao tripé universitário, na dinâmica curricular dos cursos de graduação, requer compreender a abrangência conceitual de suas atividades pelas IES, a articulação e especificidade político-pedagógica dos cursos de graduação, o protagonismo dos gestores, dos docentes e discentes em sua 
efetividade, a interdependência e interlocução dos cursos e da universidade com a sociedade e a relação com a formação dos sujeitos.

\section{CAMINHOS METODOLÓGICOS}

Do ponto de vista metodológico, a pesquisa caracterizou-se pela natureza qualitativa por meio do estudo de caso dos cursos de graduação da UFSM. Para Flick (2009), na pesquisa qualitativa não há como base um único conceito teórico ou metodológico a ser abordado, mas a construção e reflexão das estruturas do campo social, não quantificável, evidenciado através da ressignificação da prática. E o estudo de caso constituiu-se na "[...] estratégia escolhida ao se examinarem acontecimentos contemporâneos, mas quando não se podem manipular comportamentos relevantes [...]", sendo que "[...] o poder diferenciador do estudo é a sua capacidade de lidar com uma ampla variedade de evidências - documentos, artefatos, entrevistas e observações - além do que pode estar disponível no estudo histórico convencional" (YIN, 2001, p. 27). Além disso, com base em Triviños (1987) encontrou-se que o estudo de caso possibilita um conhecimento aprofundado de uma realidade delimitada.

Utilizou-se para a construção dos dados a análise dos documentos institucionais e a aplicação de questionários mistos on-line para doze coordenadores ${ }^{5}$ de cursos de graduação (que se dispuseram a participar da pesquisa). A seleção dos cursos de graduação foi determinada pela devolutiva do questionário on-line, sendo os coordenadores identificados como $\mathrm{C} 1, \mathrm{C} 2, \mathrm{C} 3$, subsequentemente de forma aleatória, e suas respostas destacadas em itálico no formato de citação mediante análise.

A aplicação do questionário misto on-line aos coordenadores de cursos de graduação da UFSM priorizou perguntas com abrangência aos seguintes aspectos: de conhecimento básico aos conceitos de extensão, concepção, as influências no meio acadêmico, a relação da extensão nos aspectos formativos no curso de graduação, percepção sobre a gestão do curso e do centro de ensino a esta nova realidade e preparação dos docentes atuantes nos cursos. A proposta foi investigar a concepção de extensão universitária por esses sujeitos, o envolvimento no processo de reformulação da matriz curricular de acordo com a nova política extensionista.

\footnotetext{
${ }^{5}$ Destaca-se que o número de gestores (doze) é menor que o número de cursos de graduação (treze) analisados, devido ao fato de que o coordenador do curso de Ciências Contábeis é gestor do curso diurno e noturno, assim fica especificado a análise de treze cursos de graduação e como sujeitos doze gestores.
} 
Para o tratamento dos dados, optou-se pela análise de conteúdo que, segundo Bardin (2016, p. 37), potencializa "o conjunto de técnicas de análise das comunicações", utilizada para descrever e interpretar o conteúdo das mais diversas classes de documentos e textos. Seguindo os preceitos desta metodologia de análise de dados, foram definidas categorias, sendo elas: categorias gerais - cursos de graduação da UFSM, inserção das ações de extensão universitária, contextos emergentes na Educação Superior; e categorias específicas - articulação político-pedagógica e especificidades dos cursos de graduação, protagonismo docente e discente, interdependência e interlocução Universidade e contextos de atuação profissional, formação de sujeitos. As categorias foram utilizadas para análise qualitativa dos dados com o propósito de direcionar as sistematizações da pesquisa para as interpretações dos documentos e das mensagens dos sujeitos colaboradores na pesquisa, a fim de compreender seus significados fora do contexto comum de leitura.

Para o processo de análise priorizou-se tabular e interpretar as respostas dos/as colaboradores/as da pesquisa, dos dados coletados quantitativamente e dos documentos, considerando pontos semelhantes e divergentes na avaliação dos resultados, sendo considerando o contexto dos seguintes cursos de graduação da UFSM: Desenho Industrial, Pedagogia Noturno, Educação Especial Diurno, Educação Especial Noturno, Programa Especial de Graduação de Formação de Professores para Educação Profissional, Farmácia, História Licenciatura, Ciências Contábeis Diurno, Ciências Contábeis Noturno, Bacharelado em Estatística, Engenharia Mecânica, Curso Superior de Tecnologia em Alimentos, Curso Superior de Tecnologia em Gestão de Turismo.

A seguir, os dados e o texto decorrente contemplam a síntese da análise da pesquisa, considerando a articulação da inserção da extensão nos PPC de cursos de graduação da UFSM e as respostas dos coordenadores, sendo apresentados os cursos que maior potencializam a implementação da política e aspectos relevantes para esta discussão.

\section{INSERÇÃO E ARTICULAÇÃO DA EXTENSÃO EM CURSOS DE GRADUAÇÃO DA UFSM}

Os cursos de graduação da UFSM analisados apresentaram diversas características na concepção formativa de seus profissionais. Pode-se constatar que os cursos de Ciências Aplicadas (Ciências Contábeis, Estatística, Desenho Industrial), 
Ciências Exatas da Terra (Estatística), Ciências Agrárias (Tecnologia de Alimentos) e Engenharias (Engenharia Mecânica), a extensão ganha a concepção de caráter assistencialista com vistas à formação "empreendedora" dos futuros profissionais, conforme é possível visualizar na resposta dos coordenadores C2 e C6:

Dentro da nossa área, não conseguimos ver muitas possibilidades de atuação na extensão além da prestação de serviço (assessorias de análise de dados) ou ensino (cursos de análise estatística fora da UFSM). (C2)

Anteriormente trabalhei no laboratório do curso que prestava serviços de Design Gráfico para a comunidade acadêmica e também comunidade em geral, no qual diversos alunos estagiaram e participaram de projetos. (C6)

Também, no PPC do curso de Engenharia essa realidade é retratada:

As atividades de extensão serão desenvolvidas através da participação dos alunos em programas de assessoria e apoio a empresas da região, conduzidas por professores do Curso, bem como em eventuais atividades de prestação de serviços realizadas nos laboratórios vinculados ao Departamento de Engenharia Mecânica, para atender necessidades específicas de empresas da região. (PROJETO PEDAGÓGICO DO CURSO DE ENGENHARIA MECÂNICA, 2019, np.).

No entanto, as questões emergentes destacadas nos cursos Tecnológicos de formação, como Gestão de Turismo, Tecnologia de Alimentos e Desenho Industrial, apresentaram características que potencializam a inserção da extensão no currículo, a partir das disciplinas complementares de graduação (DCG), da concepção, articulação e entrecruzamento do campo de prática à formação teórica dos cursos. O que justifica, também, como propulsores à dinamização da extensão no currículo, os preceitos que visam o desenvolvimento de competências e habilidades dos egressos aos cursos, sendo esta dimensão uma característica convergente pelos cursos analisados.

O Curso de Engenharia Mecânica destaca-se pela dinamização do currículo às concepções práticas desde o início de sua estruturação, assim como pelo protagonismo e incentivo discente para a realização e envolvimento de projetos de extensão e pesquisa voltados à qualificação profissional. Um aspecto emergente nesse caso é o registro de horas, pelos docentes, nas disciplinas que abarcam os projetos fora do campus universitário, a fim de "[...] fortalecer a articulação entre a teoria e prática, valorizando a pesquisa individual, coletiva e prática profissional, e atividades de extensão, colocando essas atividades como parte da carga horária", e "[...] permitir o registro de todas as atividades na carga horária, visando a formação efetiva do profissional" (PROJETO PEDAGÓGICO DO CURSO DE ENGENHARIA MECÂNICA, 2019, np.). 
Os cursos que contemplam as áreas das Ciências Humanas apresentaram, em seus Projetos Pedagógicos de Curso, a importância e o impacto social de sua formação no meio acadêmico e nas comunidades locais e regionais. Aspectos emergentes destacados são os tensionamentos e as demandas locais para a criação destes na UFSM, assim como na reformulação de seus currículos. As demandas sociais constituemse contextos emergentes à qualificação dos cursos e à ressignificação das ações extensionistas no currículo. O PPC do curso de Pedagogia noturno ilustra essa afirmação:

O Curso de Pedagogia Licenciatura Plena Noturno advém da criação do curso de Pedagogia Diurno criado em 1984, e da demanda de formação pedagógica para formação de professores em serviço, realizado através do projeto conveniado com as Secretarias de Educação dos municípios da região de Santa Maria. (PROJETO PEDAGÓGICO DO CURSO DE PEDAGOGIA LICENCIATURA PLENA NOTURNO, 2019).

Por mais que as atividades extensionistas fossem citadas nos PPC, e compreendidas como indissociáveis ao ensino e à pesquisa como aspecto relevante para a formação discente, diante das respostas dos coordenadores e na análise dos documentos, ficou pontual que as ações extensionistas são sinalizadas como atividades complementares. Por exemplo, essa realidade está retratada na resposta do seguinte coordenador:

No caso de inclusão de projetos e programas de extensão nos currículos, temos um problema, são os professores (não o curso) que criam e cadastram projetos e programas de extensão. E quando esses professores não quiserem mais coordenar tais projetos ou encerrarem os mesmos, como fica a situação. (C2)

Também, encontra-se subsídio para esta questão na análise apresentada por Rosso (2019, p. 162) sobre o Projeto Pedagógico do Curso de História - Licenciatura, da UFSM:

Em suas estratégias pedagógicas, o PPC destaca a contemplação de 210h da carga horária do curso destinada a Atividades Complementares de Graduação (ACG). Sendo a carga horária flexível cumprida em atividades teórico-práticas, de acordo com o interesse e planejamento dos estudantes.

Nesses casos, as atividades de extensão ficam à mercê do interesse e envolvimento dos docentes e discentes em realizá-las. Ou seja, não basta aspectos normativos, decorrentes de políticas educacionais em âmbito nacional, local e institucional, para que as ações de extensão no contexto curricular dos cursos de graduação se efetivem. 
Segundo Sousa (2010), a extensão universitária, como uma das funções acadêmicas, tem sofrido dificuldades na construção de seu conceito. Sua concepção, quando identificada, toma proporções individuais, sem maiores cuidados de uma construção teórica e mesmo histórica. A polissemia, segundo a autora, é uma constante ao propósito da extensão.

A falta de clareza conceitual acaba por provocar maior depreciação do status da extensão dentro da universidade. Afinal, não se identifica o que pode ser a prática extensiva e muitas vezes a confusão com o ensino e a pesquisa torna mais difícil essa identificação. Tentar clarear como atividades independentes tornam esta tarefa um esforço inútil, pois as atividades se completam e se mesclam umas às outras. (SOUSA, 2010, contra capa).

A autora destaca que, diante da complexidade do conceito de prática e de teoria da extensão, cabe à Universidade priorizar o aprofundamento de pesquisas na área e sua concepção individual, reafirmar as políticas vigentes para sua efetivação e legitimar a importância que a extensão exerce na Instituição de Ensino Superior.

Em análise as respostas dos coordenadores para investigação dos movimentos do curso, com relação ao atendimento da política nacional de inserção dos $10 \%$ de ações extensionistas em créditos curriculares, verificou-se uma forte evidência na falta de clareza e concepção da extensão como aspecto formativo e articulado aos preceitos e dinâmicas curriculares do curso, que tensionam a efetivação de sua qualidade. Esta realidade é observada em algumas respostas de colaboradores da pesquisa:

[...] os colegas têm muitas dúvidas de como implantar as ações no currículo, bem como sobre o que é extensão. Estamos nos reunindo para discutir tais questões. Esse é um assunto que retorna frequentemente. (C12)

[...] maior desafio para atendimento da política extensionista é de elencar tais atividades possíveis junto à comunidade do curso de modo que estas possam ser incorporadas à matriz curricular. (C5)

[...] Quanto às "disciplinas de extensão", temos dois problemas: muitas disciplinas "matemáticas" e de "teoria matemática e de probabilidade", e o fato do Curso ser noturno, onde $40 \%$ dos alunos não poderão participar de ações de extensão durante o dia. (C2).

A inserção de extensão, de acordo com as respostas, é concebida por disciplinas isoladas e/ou específicas que compreendem carga horária complementar do curso, ou em disciplinas metodológicas que enfatizam a ação da pesquisa. A esta concepção, Silva (2000) discute as três abordagens de extensão universitária no contexto da universidade: funcionalista, crítica e processual. Segundo a autora, essas concepções possibilitam compreender a função atribuída pela universidade ao meio social. 
$\mathrm{Na}$ perspectiva funcionalista, a extensão é entendida pela realização de cursos, apenas como prestação de serviços assistenciais. A perspectiva crítica compreende a extensão a partir do ensino e da pesquisa, comprometidos com a realidade e essa abordagem exige uma nova postura formativa da universidade junto a sociedade na articulação do tripé ensino, pesquisa e extensão, ou seja: "A extensão representa uma etapa dependente, inerente, implícita na produção e disseminação do conhecimento" (SILVA, 2000, p. 103). Já na perspectiva processual, de acordo com Silva (2000, p. 104), a "[...] extensão possui uma tarefa institucional e, com isso, um espaço próprio de organização política e estrutural da universidade", representando, a partir de sua institucionalização, "[...] uma espécie de consciência social da universidade, instigando-a a absorver as demandas da sociedade e trazê-las para o seu interior", para além de alimentar o ensino e a pesquisa com os dados da realidade.

Também, cabe mencionar que a ruptura do paradigma de uma extensão funcionalista requer tensionamento e sensibilização da universidade para a valorização das ações no currículo e para o atendimento e esclarecimento de dúvidas, tão apontadas pelos coordenadores sobre sua inserção. A maior incidência aos anseios dos cursos ocorreu ao esclarecimento da política educacional vigente, a adequação da carga horária e a adequação dos currículos dos cursos noturnos, conforme destacado pelo coordenador C2 anteriormente e pelo coordenador C11 ao explanar sua preocupação: "[...] como ter a participação de alunos do turno noturno; como aplicar extensão nas empresas se não podemos trazê-las até aqui, nem levar todos os alunos”.

Ao responderem o questionamento sobre a frequência de reuniões ou formação, na UFSM, com o foco na extensão universitária, cinco dos coordenadores afirmaram haver formações referentes, e sete alegaram não terem participado de reuniões entre outras atividades sobre o tema. Os coordenadores que responderam positivamente sinalizaram uma incidência relativamente baixa de encontros, ficando restritos aos seus departamentos e aos professores que atuam na área da extensão: "[...] uma vez no semestre" (C3). "Desde que ingressei na coordenação, em junho de 2017, apenas uma reunião" (C7). "Reuniões realizadas nos departamentos dos professores que atuam na extensão" (C1). Essa incidência reforça a afirmativa de Silva (2000) sobre a valorização das atividades extensionistas pelas IES e a crítica construtiva dos coordenadores sobre a necessidade de discussão da política extensionista na universidade.

No entanto, no decorrer da pesquisa, constatou-se que a UFSM passou a investir na promoção de encontros para discussão e construção da política institucional de extensão, assim como no esclarecimento da concepção de inserção da extensão no 
currículo dos cursos de graduação. O coordenador C12 aponta esse movimento da Universidade:

\begin{abstract}
A frequência foi boa, um total de três encontros até o momento. Participei de uma reunião com a Pró-reitoria de Extensão quando estavam formulando a política de Extensão em julho de 2018 e outro na JAl, em outubro do mesmo ano. Na JAl foi ministrada uma palestra sobre ações de extensão: programas, eixos da extensão, projetos, cursos oferecidos à comunidade externa da UFSM, etc. Em 2019 foi realizada outra palestra aos professores do nosso centro, mas não pude participar.
\end{abstract}

Segundo a Resolução CNE/CES n 07/2018, que prevê as Diretrizes para a Extensão na Educação Superior Brasileira, às IES foi estipulado o prazo até 2021 para a implantação do disposto na política extensionista nacional, o que poderá potencializar impactos quanto ao protagonismo docente nas ações de extensão na universidade.

No entanto, em destaque à frequência de reuniões nos departamentos, o coordenador do curso de Engenharia Mecânica, curso que potencializa a extensão como aspecto formativo, destaca o envolvimento dos docentes em atender as demandas de formação da Empresa Júnior no curso, sinalizando: "Todo o projeto de extensão tem reuniões periódicas. Considerando a empresa júnior, há reuniões semanais para acompanhamento das tarefas". Tal gestor considera os movimentos de autoavaliação das atividades de extensão como indicador de qualidade dos processos formativos no currículo do curso.

Em análise aos PPC, tornou-se possível verificar os diversos tensionamentos histórico-políticos vividos em cada época pelos cursos, assim como a superação das demandas formativas ressignificando aspectos curriculares relacionados às políticas públicas e aos contextos de atuação profissional. Assim, tornou-se possível visualizar como o currículo de cada curso de graduação pesquisado vem sendo reformulado e quais elementos estão ou não inter-relacionados à extensão universitária.

Constatou-se, dos treze PPC analisados, o curso de Bacharelado em Farmácia, efetivamente, no momento da pesquisa, fazendo a previsão da extensão articulada ao currículo, justamente, por contemplá-la em sua matriz como aspecto formativo do acadêmico na área. Como um de seus princípios, além de evidenciar a formação técnica, ética, científica, política e humana, o documento apresenta: "[...] espera-se que este profissional deve estar apto, ainda, a atuar no ensino farmacêutico, bem como em atividades de pesquisa e extensão desenvolvidas em órgãos públicos ou privados. (PROJETO PEDAGÓGICO DO CURSO DE FARMÁCIA, 2018, np.). O PPC ainda aborda que o curso volta-se para práticas que se distanciam das ações tradicionais de extensão, 
com vistas a uma postura acadêmica engajada na atuação social, a partir de ações que possibilitem a operacionalização do ensino, da pesquisa e da extensão inter-relacionadas as áreas de conhecimento do curso.

A proposta pedagógica é que o estudante tenha no máximo $30 \mathrm{~h}$ de aula semanais, para que possa ter horários disponíveis para se envolver em projetos de extensão, pesquisa, estágios e outras atividades complementares. [...] Buscamos também a interdisciplinaridade visando repensar o profissional quanto à sua formação humana e técnica generalista. (PROJETO PEDAGÓGICO DO CURSO DE FARMÁCIA, 2018, np.).

Para o atendimento da política de inserção da extensão no currículo, o coordenador do curso de Farmácia, em resposta ao questionário, destacou como desafio para a efetivação da carga horária do curso, a formação e o protagonismo docente, "[...] tendo em vista a carga horária do curso, incluindo unidades curriculares e estágios, e a formação profissional necessária, nosso desafio está sendo adequar a carga horária necessária em atividades de extensão, e motivar os docentes".

Esta ação já vinha sido apresentada pelos demais coordenadores como um aspecto emergente para efetivação da política de extensão, e cabe destacar que a análise dos PPC e a aplicabilidade do questionário on-line ocorreram durante a reformulação e aprovação da política institucional de extensão na UFSM em 2019, após quatro meses da homologação das Diretrizes de Extensão em âmbito Nacional, a Resolução nº 07/2018.

Os documentos normativos da Universidade ainda não haviam sido modificados e reformulados de acordo com as considerações da nova política extensionista, sendo atribuído um prazo até 2021 para as Universidades, juntamente aos cursos e seus NDE, para atendimento às normativas nacionais. Com isso e em relação aos tensionamentos e movimentos do Curso de Farmácia quanto a normatização da política de extensão, o coordenador respondeu:

\footnotetext{
Atualmente, estamos mapeando estas atividades junto ao corpo docente. Além dos projetos já existentes que integram os alunos do curso, estamos planejando a criação de disciplinas e a inclusão de atividades de extensão em disciplinas existentes para atender a demanda. Estamos em constante reuniões com os professores para adequar suas disciplinas contemplando, se possível, uma carga horária em atividades de extensão. Além de solicitar orientações, pois temos algumas dúvidas.
}

Ao mesmo tempo em que o colaborador aponta as dúvidas referentes à carga horária a ser inserida, é possível perceber o movimento para a definição de estratégias de adequação. 
Quanto a incidência de disciplinas e ações de extensão universitária no currículo de cursos de graduação da UFSM, nove dos coordenadores, dos doze participantes da pesquisa, sinalizaram não haver ações ou disciplinas de conotação extensionista no currículo dos cursos de graduação, o que corrobora a análise dos PPC. Esse aspecto está destacado em algumas das respostas referentes a adequação da nova política:

Estamos em constante reuniões com os professores para adequar suas disciplinas contemplando, se possível, uma carga horária em atividades de extensão. Além de solicitar orientações, pois temos algumas dúvidas. (C1).

O curso está em processo de reformulação curricular. As ações estão sendo pensadas na inserção em disciplinas já existentes, e criação de novas disciplinas relacionadas. (C7).

O NDE estará discutindo a inserção da extensão no itinerário formativo no âmbito do currículo e os encaminhamentos dados a esta dinâmica acontecerão posterior discussão. (C5).

Entretanto, três coordenadores confirmaram haver ações de extensão que integram o currículo nos cursos em que atuam, sendo sua abrangência com relação a realização de projetos, a exemplo das falas: "A extensão ainda é realizada somente através de projetos" (C9). "Projetos de extensão liderados pelos professores" (C4).

Outro destaque, sob análise das respostas dos coordenadores, diz respeito a grande incidência de projetos de extensão nos PPC para o atendimento da política extensionista. Compreende-se pela política de extensão da UFSM, conforme a Resolução UFSM $n^{\circ}$ 06/2019, que as ações de extensão pela modalidade de projetos se referem ao "[...] conjunto de ações processuais, de caráter educativo, artístico, social, cultural, assistencial, tecnológico, político ou de suporte institucional externo, com objetivo específico e prazo determinados de até cinco anos, renovável." (UNIVERSIDADE FEDERAL DE SANTA MARIA, 2019, p. 04).

A categoria de projetos, também, compreende a modalidade de programa, classificada pela política como "[...] um conjunto de ações de extensão (projetos, cursos, eventos ou prestação de serviços, integrado a atividades de pesquisa e ensino, com caráter multidisciplinar e orgânico institucional, com integração no território e/ou grupos populacionais" (UNIVERSIDADE FEDERAL DE SANTA MARIA, 2019, p. 3). Segundo Martins (2008), projetos de extensão possibilitam ampliar a atuação do campus universitário para além do que realmente se espera, tendo o formato mais comum e prático, focado na realização de ações que aproximam a universidade das demandas sociais. 
Dalla Corte (2010, p. 195) aponta para uma perspectiva de reflexão quanto a proposta e a incidência apontada pelos cursos, considerando a criação e a adaptação de disciplinas, para atendimento da política de inserção das ações extensionistas, com a proposição de constituir estratégias formativas para interlocução de saberes e fazeres ao longo do curso. Também, Goulart (2004) discute a extensão na perspectiva do ensino e articulada à pesquisa, como uma grande propulsora de produção de conhecimento, em que o estudante em contato com o contexto de sua futura profissão, poderá complementar seu aprendizado com base na interação com mundo, da troca de vivências e da leitura que faz dele, a partir dos conhecimentos pessoais e acadêmicos. Para o autor, a extensão com o caráter de ensino efetiva a aprendizagem diante da indissociabilidade com a pesquisa, o que cabe nesse estudo, também, a sua inserção no currículo. As discussões dos autores reforçam a perspectiva de que a responsabilidade das ações de extensão também cabe aos cursos de graduação e não somente a outros setores da universidade. Ou seja, cabe promover a execução das ações extensionistas, a partir das mesmas perspectivas formativas de planejamento do curso e eixo de integração das disciplinas, ao atendimento do estágio supervisionado (GOULART, 2004), entre outros aspectos.

Ainda, Goulart (2004, p. 34) enfatiza que "[...] assim planejadas, as atividades de extensão poderão incluir todos os estudantes, operando, inclusive, em consonância com o ensino e com a pesquisa, de forma que elas sejam também atividades produtoras de conhecimento", trazendo os cursos noturnos, tão apontados como desafiantes à inserção da política pelos coordenadores, a importância da flexibilização do currículo e o planejamento em conjunto, para o atendimento de suas especificidades e as articulações realizadas.

\section{CONSIDERAÇÕES FINAIS}

Nas discussões apresentadas ao longo do texto, passou-se a compreender que a extensão se faz não somente por ações assistencialistas e/ou de prestação de serviços, mas por toda a relação de formação que a universidade realiza e possibilita aos diferentes contextos, setores e sujeitos sociais. Nesse sentido, refletiu-se que a sociedade não se faz paralela ou subjacente à universidade, ou seja, a sociedade compõe a universidade que é representada pelos sujeitos que dela necessitam, transitam, frequentam, trabalham e estudam. 
Por mais que as tendências das políticas educacionais e os documentos normativos direcionam para a indissociabilidade do tripé universitário, para ações extensionistas articuladas aos preceitos formativos de cada área profissional, a inserção da extensão no currículo poderá potencializar aderência e legitimação nos e dos processos formativos (na dinâmica curricular) a partir da concepção da extensão atribuída pelos sujeitos que efetivam ou não tais ações da universidade e dos cursos de graduação. Isso impacta na articulação político-pedagógica dos cursos de graduação, no protagonismo docente e discente com relação às atividades de extensão e de ensino, a interlocução e inter-relação da universidade com a interna e externa, dos cursos e na formação dos sujeitos.

Para uma nova concepção de universidade, a partir dos tensionamentos das políticas extensionistas, torna-se necessária a quebra de paradigmas de formação técnico-científica para uma transposição epistemológica mais formativa e emancipatória do contexto socioeducacional. Essa perspectiva é que, de fato, se constitui emergente, no que tange à extensão universitária na atualidade.

Esta pesquisa permitiu inferir que historicamente a extensão vem assumindo um caráter assistencialista, mas que, gnosiologicamente, tem sido compreendida como ato de estender. $E$ isso não pressupõe prática dialógica da universidade com a sociedade. A proposta de cursos, programas, projetos ou, ainda, a criação de disciplinas com caráter extensionista não resolve o gargalo que estremece o tripé universitário. Se existe a pretensão da extensão como subsídio para fortalecimento dos processos formativos da e na universidade em inter-relação com a sociedade e suas demandas, assim como esses processos se deem de maneira democrática e interdependente, é preciso romper a ideia de extensão como ato de estender, seja por qual ação extensionista for. Há, então, uma forte influência político-ideológica que subsidia, ainda, tal compreensão da extensão no currículo superior: o neoliberalismo, a necropolítica, sendo esta pauta reservada para uma próxima discussão.

Na busca de reconhecer as ações de extensão universitária presentes no currículo de cursos de graduação da UFSM em contextos emergentes, verificou-se que, dos treze cursos de graduação pesquisados, dois cursos destacam-se como emergentes justamente pelas considerações acerca da política extensionista: o curso de Farmácia que já apresenta a extensão integrada a matriz curricular, e o curso de Engenharia Mecânica que destacou-se pelos movimentos realizados a partir da oferta, estímulo aos estudantes, registro e concepção das ações práticas e extensionistas em sua matriz curricular. 
Constatou-se, também, diversos desafios para a efetivação da extensão no currículo dos cursos de graduação da UFSM, podendo ser destacados os seguintes: esclarecimento e compreensão de quais ações extensionistas são possíveis de serem incorporadas à matriz curricular; conscientização dos professores e estudantes acerca da importância e contribuições da extensão no currículo do curso; participação contínua da comunidade nas ações extensionistas; acessibilidade da universidade a empresas e viceversa; inclusão de projetos de prestação de serviços financiados por empresas; abrangência do maior número de estudantes nas ações de extensão; adequação do aluno trabalhador e dos cursos noturnos; articulação entre os cursos, perfil dos alunos e disponibilidade para atividades práticas; viabilização da carga horária aos tempos de curso; vinculação de um grupo maior de docentes aos cursos que demandam responsabilidade técnica e profissional; motivação e comprometimento dos docentes, considerando a compreensão da abrangência e implicações da política de extensão; viabilização das ações de extensão para além da prestação de serviço ou ensino diante os cursos da área das Ciências Exatas.

Além disso, passou-se a compreender que conceber a extensão como componente curricular requer um PPC alinhado aos significados da profissão e aos interesses de formação e atuação profissional. Consiste no atendimento das demandas na sociedade, desenvolvimento de competências e habilidades para o entrecruzamento da teoria e prática diante aos preceitos de cada curso, que configuram a problematização e sistematização dos conhecimentos com as emergências da profissão e sua prática.

A partir dessas perspectivas decorrentes da pesquisa, conclui-se que a inserção da extensão no currículo está para além de uma efetivação normativa nos cursos de graduação. Sua legitimidade apresenta-se pela ação dos sujeitos envolvidos em sua efetivação (docentes, discentes e todos que constituem os processos formativos do curso), por meio das vivências e demandas da área.

A inserção da extensão na matriz curricular pode potencializar a perspectiva de qualidade na formação profissional, o que requer docentes e estudantes protagonistas e produtores de conhecimento científico e socioeducacional. Portanto, a extensão agregada ao currículo de cursos de graduação poderá alcançar seu viés formativo tendo por base, por exemplo: articulação dos preceitos formativos de cada curso em ações interdisciplinares; elaboração e consecução de propostas metodológicas de inserção social; levantamento de demandas sociais/profissionais do curso em formação; avaliação diagnóstica do curso em suas práticas e estágios, a fim de intensificar os preceitos formativos nas ações extensionistas; interlocução entre cursos, comunidade acadêmica e 
sociedade; esclarecimento e compreensão de quais ações extensionistas são possíveis de serem incorporadas à matriz curricular.

A inserção da extensão no currículo nos cursos de graduação é emergente, uma vez que, diante dos PPC analisados, ainda ocupa a posição de atividade complementar. Nessa direção, apresenta-se como desafio no que se refere às especificidades de cursos de graduação que conferem a carga horária, o perfil, a formação discente, o protagonismo docente na efetivação das atividades, a concepção de extensão e compreensão no currículo como campo formativo acadêmico indissociável juntamente com a pesquisa e o ensino.

No momento que a extensão se encontrar desarticulada da pesquisa e do ensino, esta poderá não estender os conhecimentos necessários para qualificação do fazer pedagógico dos cursos, e nem na efetividade dos conhecimentos que balizam a formação acadêmica de cada área profissional. Portanto, o investimento na compreensão das políticas e práticas extensionistas possibilita romper com a linearidade da organização curricular dos cursos de graduação e a perspectiva assistencialista da função social da Universidade.

\section{REFERÊNCIAS}

BARDIN L. Análise de conteúdo. São Paulo: Edições 70, 2016.

BRASIL. Lei no 13.005 de 25 de junho de 2014. Aprova o Plano Nacional de Educação PNE e dá outras providências. Diário Oficial da União, Poder Legislativo, Brasília, DF, 26 jun. 2014. Seção 1, p. 1. Disponível em: <http://www2.camara.leg.br/legin/fed/lei/2014/lei13005-25-junho-2014-778970-publicacaooriginal-144468-pl.html> Acesso em: 19 set. 2018.

BRASIL. Resolução CNE/CES nº 07, de 18 de dezembro de 2018. Estabelece as Diretrizes para a Extensão na Educação Superior Brasileira e regimenta o disposto na Meta 12.7 da Lei no 13.005/2014. Diário Oficial da União, Brasília, DF, 19 dez. 2018, Seção 1, p. 49 e 50. Disponível em:

<http://portal.mec.gov.br/index.php?option=com_docman\&view=download\&alias=104251rces007-18\&category_slug=dezembro-2018-pdf\&ltemid=30192> Acesso em: 12 abr. 2019.

DALLA CORTE, M. G. O Estágio Curricular e a Formação se Qualidade do Pedagogo. 2010. 315 p. Tese (Doutorado em Educação). Pontifícia Universidade Católica do Rio Grande do Sul, Porto Alegre, RS, 2010. Disponível em:

<http://tede2. pucrs.br/tede2/bitstream/tede/3678/1/430801.pdf> Acesso em: 28 out. 2019. 
DALLA CORTE, M. G. Um estudo acerca dos contextos emergentes nos cursos de licenciatura no Brasil: em destaque a internacionalização. Revista Educação. Porto Alegre, v. 40, n. 3, p. 357-367, set-dez. 2017. ISSN 1981-2582.

DOI: http://dx.doi.org/10.15448/1981-2582.2017.3.29023. Disponível em:

<http://revistaseletronicas.pucrs.br/ojs/index.php/faced/article/view/29023/16529>. Acesso em: 05 out. 2019.

FLICK, U. Introdução à pesquisa qualitativa. Tradução Joice Elias Costa. 3.ed. Porto Alegre: Artemed, 2009.

FORPROEX. Política Nacional de Extensão Universitária. Manaus, 2012. Disponível em: <http://w3.ufsm.br/pre/index.php/a-pre-2/legislacao>. Acesso em: 28 nov. 2018.

GADOTTI, M. Extensão universitária: para quê? Instituto Paulo Freire, São Paulo, SP, 15 fev. 2017. Disponível em: <http://www.paulofreire.org/noticias/557-extensaouniversitaria-para-que> Acesso em: 02 nov. 2018.

GADOTTI, M. Qualidade na Educação: uma nova abordagem. COEB: Congresso de Educação Básica: Qualidade na Aprendizagem. Rede Municipal de Ensino de Florianópolis. Florianópolis: SC, 14 fev. 2013. Disponível em: <http://www.pmf.sc.gov.br/arquivos/arquivos/pdf/14_02_2013_16.22.16.85d36816927867 26aa2c7daa4389040f.pdf> Acesso em: 10 out. $201 \overline{9}$.

GOULART, A. T. A importância da pesquisa e da extensão na formação do estudante universitário e no desenvolvimento de sua visão crítica. Horizonte - Revista de Estudos de Teologia e Ciências da Religião, v. 2, n. 4, p. 60-73, 31 mai. 2004. Disponível em: $<$ http://webcache.googleusercontent.com/search?q=cache:6AfGB9nrm1kJ:periodicos.puc minas.br/index.php/horizonte/article/view/580+\&cd=1\&hl=pt-BR\&ct=clnk\&gl=br $>$ Acesso em: 03 nov. 2019.

IMPERATORE, S. L. B.; PEDDE, V. "Curricularização” da Extensão Universitária no Brasil: questões estruturais e conjunturais de uma política pública. In: XIII CongresoLatinoamericano de ExtensiónUniversitaria. 2015, Havana. Anais. Disponível em: <http://www.congresoextension.mes.gob.cu/documentos/CLEU\%20(VF).pdf> Acesso em: 10 abr. de 2018.

JAPIASSU, H. Alguns instrumentos conceituais; O que é a epistemologia? In.: Introdução ao pensamento epistemológico. Rio de Janeiro: Francisco Alves, 1991.

LUNARDI, E. M. Qualidade da Gestão Pedagógica no Curso de Pedagogia. 2012. 262 p. Tese (Doutorado em Educação). Porto Alegre, RS: Pontifícia Universidade Católica do Rio Grande do Sul., Porto Alegre, RS, 2012. Disponível em:

<http://tede2.pucrs.br/tede2/bitstream/tede/3740/1/446275.pdf> Acesso em: set. 2019. 
MARTINS, E. F. Extensão como componente curricular: oportunidade de formação integral e de solidariedade. Ciência e Cognição 2008, vol. 13 (2), p. 201-209, jul. 2008. ISSN 1806-5821. Disponível em:

<http://www.cienciasecognicao.org/revista/index.php/cec/article/view/232/131> Acesso em: 12 out. 2019.

MAUÉS, O. C. Ensino superior na ótica dos organismos internacionais. Educar em revista, Curitiba, Brasil, vol. 35, n.75, p. 13-30, mai/jun., 2019. ISSN 1984-0411. Disponível em: <http://www.scielo.br/scielo.php?pid=S010440602019000300013\&script=sci_arttext\&tlng=pt> Acesso em: 22 set. 2019.

MAZZILLI, S. Ensino, pesquisa e extensão: reconfiguração da universidade brasileira em tempos de redemocratização do estado. RBPAE: Revista Brasileira de Política e Administração da Educação. Periódico científico editado pela Anpae. v. 27, n. 2, p. 205221, mai/ago. 2011. Disponível em: <https://seer.ufrgs.br/rbpae/article/view/24770/14361> Acesso em: 19 set. 2019.

MOROSINI, M. C. Qualidade da Educação Superior e Contextos Emergentes. Revista Avaliação, Sorocaba, SP, v. 19, n. 2, jul. 2014. Disponível em:

<https://www.scielo.br/pdf/aval/v19n2/a07v19n2.pdf> Acesso em: 02 out. 2019.

MOTTA, R. A. Tecnologia educacional no ensino superior: cenários da educação a distância e a avaliação institucional. In: COLOMBO, Sonia S. (Org.). Gestão universitária: os caminhos para a excelência. Porto Alegre: Penso, 2013.

RENEX. Rede Nacional de Extensão, 2016. Sobre o FORPROEX e a RENEX. Apresentação. Disponível em: < https://www.ufmg.br/proex/renex/index.php/apresentacao/forproex-erenex\#: :text=O\%20F\%C3\%B3rum\%20de\%20Pr\%C3\%B3Reitores,e\%20o\%20fortalecimento\%20da\%20democracia.> Acesso em: 08 de out. de 2020.

RODRIGUES, Â. R. A extensão universitária: indicadores de qualidade para avaliação de sua prática/ Estudo de caso em um centro universitário privado. 2003. 182 p. Dissertação. (Mestrado em Engenharia de Produção, Área: Planejamento e Gestão Estratégica) - Programa de Pós-Graduação em Engenharia de Produção, Universidade Federal de Santa Catarina, Florianópolis, SC, 2003. Disponível em: $<$ https://repositorio.ufsc.br/bitstream/handle/123456789/86224/225491.pdf?sequence=1\&i sAllowed=y> Acesso em: 04 dez. 2018.

ROSSO, G. P. Inserção das ações de extensão nos cursos de graduação da UFSM na perspectiva dos contextos emergentes. 2019. 252 p. Dissertação (Mestrado) Universidade Federal de Santa Maria - Programa de Pós-graduação em Educação. Santa Maria, RS, 2019. 
SANTOS, B. S. A universidade no século XXI: para uma reforma democrática e emancipatória da Universidade. 3 ed. São Paulo: Cortez, 2011. v. 11.

SILVA, M. das G. M. Extensão: a face social da universidade? Campo Grande: Editora da UFMS, 2000.

SOUSA, A. L. L. A história da Extensão Universitária. $2^{\mathrm{a}}$ ed. Campinas, SP: Editora Alínea, 2010.

TRIVIÑOS, A. N. Introdução à pesquisa em Ciências Sociais: a pesquisa qualitativa em educação. São Paulo: Atlas, 1987.

UNIVERSIDADE FEDERAL DE SANTA MARIA. Projeto Pedagógico do Curso de Engenharia Mecânica - UFSM, Santa Maria 2019. Disponível em: <https://www.ufsm.br/cursos/graduacao/santa-maria/engenhariamecanica/projetopedagogico> Acesso em: 22 out. 2019.

UNIVERSIDADE FEDERAL DE SANTA MARIA. Projeto Político Pedagógico do Curso de Farmácia, Santa Maria, 2018. Disponível em:

<https://www.ufsm.br/cursos/graduacao/santa-maria/farmacia/projeto-pedagogico>. Acesso em: 16 out. 2019.

UNIVERSIDADE FEDERAL DE SANTA MARIA. Projeto Pedagógico do Curso de História - Licenciatura - UFSM, Santa Maria, 2017. Disponível em: <https://www.ufsm.br/cursos/graduacao/santa-maria/historia/projeto-pedagogico> Acesso em: 19 out. 2019.

UNIVERSIDADE FEDERAL DE SANTA MARIA. Projeto Pedagógico do Curso de Pedagogia Licenciatura Plena Noturno - UFSM, Santa Maria, 2007. Disponível em: <https://portal.ufsm.br/ementario/curso.html?idCurso=1061>. Acesso: 15 out. 2019.

UNIVERSIDADE FEDERAL DE SANTA MARIA. Resolução n 16/2008. Política de Extensão da UFSM, Santa Maria, 2008. Disponível em:

<http://w3.ufsm.br/pre/index.php/a-pre-2/legislacao\#normas-gerais-ufsm>.Acesso em: 30 out. de 2018.

UNIVERSIDADE FEDERAL DE SANTA MARIA. Resolução n 006/2019. Aprova a Política de Extensão da Universidade Federal de Santa Maria. Santa Maria, 2019. Disponível em: <https://portal.ufsm.br/documentos/publico/documento.html?id=12476803> Acesso em: 13 ago. 2019.

YIN, R. Estudo de caso: planejamento e métodos. 2a ed. Porto Alegre: Bookman; 2001. 